\title{
Research on the Performances of Heat-Sealing BOPP Film
}

\author{
Influence of coating thickness
}

\author{
Jie Du \\ College of Materials and Chemistry Engineering, \\ Hainan University, \\ Haikou 570228, China \\ E-mail: dujie@hainu.edu.cn \\ Shuna Meng \\ College of Materials and Chemistry Engineering, \\ Hainan University, \\ Haikou 570228, China \\ Shiwei Lin \\ College of Materials and Chemistry Engineering, \\ Hainan University, \\ Haikou 570228, China
}

\author{
Lei Ding \\ College of Materials and Chemistry Engineering, \\ Hainan University, \\ Haikou 570228, China
}

\author{
Hongcun Huang \\ Sainuo Industrial Co., Ltd \\ Haikou 570125, China
}

Tan Li

Sainuo Industrial Co., Ltd

Haikou 570125, China

\begin{abstract}
Heat-sealing BOPP films are used widely as commercial packages in recent years. However, nowadays there are some obstacles in heat-sealing BOPP films producing, for example the heat sealing strength is relatively low, which makes heat-sealing BOPP films not satisfy the increasing demands of the modern packagings with highperformances. Therefore, an effective reseach on the relationship of the performences of BOPP film and its physical parameters is in great need. In this paper, we tested various performance indicators of heat-sealing BOPP films with different surface coating thickness. The results showed that heat-sealing strength and haze of BOPP films significantly changed with different coating thickness, while the friction coefficient did not change obviously.
\end{abstract}

Keywords- heat -sealing strength; temperature; thickness; haze; friction coefficient

\section{INTRODUCTION}

The heat-sealing strength of the plastic layers is the same or different materials fills the heat-bonded together at a certain temperature and pressure, and then the peel strength is reached. Biaxial Oriented Polypropylene (BOPP) is a very important product in the package field [1-3]. It is a kind of waterproof and high mechanical specification material, and it is size-stabled and very light without any smell and poison. But usually its heat sealing strength is generally only $10 \mathrm{~N} / 15 \mathrm{~mm}$, lower than the extensive use of composite membrane or coating film in the market (the heat-sealing strength is usually 20N/15mm).

To achieve a single layer environmental film instead of the multilayer composite membrane or coating film, we must further improve its heat-sealing strength through a study on the relationship between physical parameters and performances of BOPP films. This project aims at the systematic study of the composition and structure of sealing materials for films, to establish a composition structure - function relationship, and examine how the seal strength, haze and friction coefficient change with the variation of the thickness.

\section{MATERIAL AND TECHNIQUES}

Brugger HSG-C Heat seal tester (Beijing Dan Beier Instrument Co., Ltd); WGT-S Transmittance haze meter (Beijing Science and Technology Co., Ltd. baiyuan Ark); MXD-01 Coefficient of friction tester (GREAT Ling Technology Co., Ltd. in Jinan).

These co-extruded films were made with three layers. One central layer of homopolymer of polypropylene (i-PP) (95.5\%). The two external layers were manufactured using a random copolymer of poly propylene and $3 \%$ of polyethylene-polybutylene as raw materials. Some additives, as antiblocking and slipagents, were added in quantities less than 1000 ppm. The core layer represents $90 \%$ and the skin layers $10 \%$ of the film. This compounding was confirmed by micro thermal analysis.

\section{RESUlTS AND DisCUSSION}

\section{A. Manufacture BOPP}

The production line of the film is a BRÜCKNER BOPP tenter-frame line, of sequential stretching, nominal out-put $1200 \mathrm{~kg} \mathrm{~h}^{-1}$ and $6 \mathrm{~m}$ final width. The following scheme shows the different steps of the production line. 
Both of main extruder and coextruders used monoscrews. As the raw materials are melted, the melt mass goes through a heated pipeline to a flat die at $250{ }^{\circ} \mathrm{C}$. The polymer is cooled very fast and melt mass goes down on a chill roll at the temperature of $28-33{ }^{\circ} \mathrm{C}$. Then, the crystallization is produced and this material is called cast film (Fig. 1).

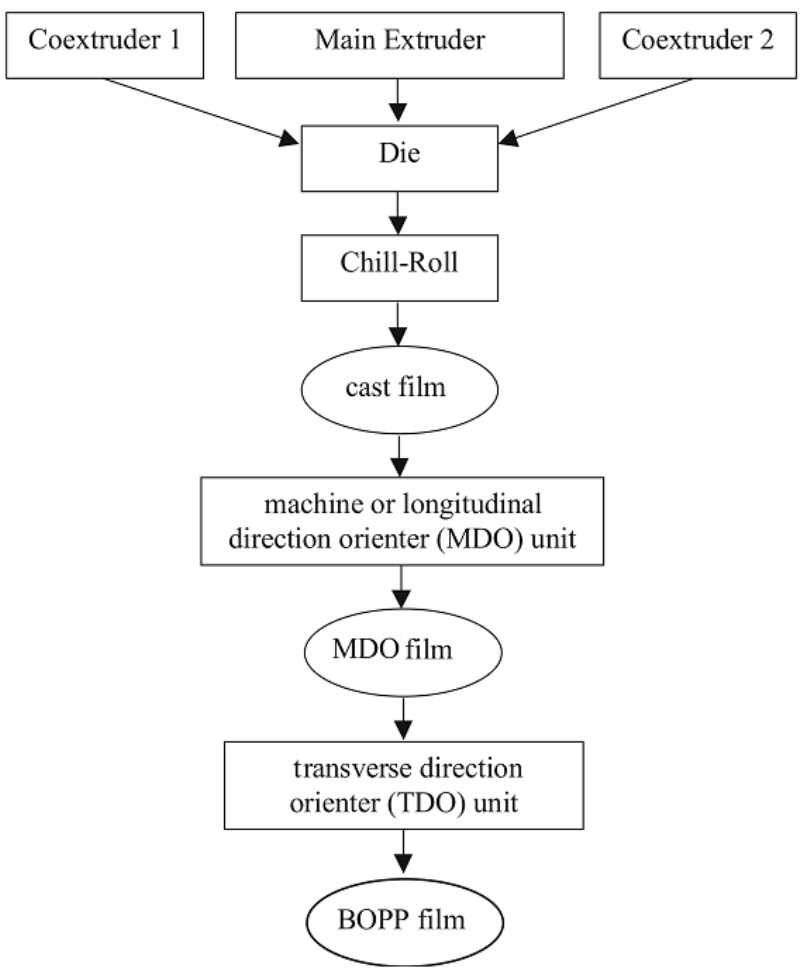

Figure 1. The manufacture of BOPP.

\section{B. Heat sealing strength changing with the thickness and temperature}

Three-layer (represented by A, B, C) BOPP films were manufactured with the above methods. Surface A was coated with polyvinyl alcohol, surface $C$ was coated with acrylic, and surface B is BOPP film (Thickness of 20um). The coating thicknesses are $0.8 \mathrm{um}, 1.0 \mathrm{um}, 1.2 \mathrm{um}, 1.5$ um, $1.8 \mathrm{um}$, and $2.0 \mathrm{um}$, respectively. We used Brugger HSG-C heat sealing tester to detect how the heat-sealing strengths of $\mathrm{A} / \mathrm{A}, \mathrm{A} / \mathrm{C}$, and $\mathrm{C} / \mathrm{C}$ interfaces change with temperature and coating thickness (Fig. 2). The heat sealing strength on A/A interface increases obviously with increasing temperature below $120{ }^{\circ} \mathrm{C}$, while has a little change above $120{ }^{\circ} \mathrm{C}$. At the same heat-sealing temperature, the heat sealing strength increases with higher coating thickness. The heat sealing strength on $\mathrm{A} / \mathrm{C}$ interface increases significantly till $110{ }^{\circ} \mathrm{C}$, while increases gradually between $110^{\circ} \mathrm{C}$ and $120^{\circ} \mathrm{C}$, and decreases above $120^{\circ} \mathrm{C}$. Similar trend of the heat sealing strength with different coating thickness as A/A interface is also showed in Fig. 2. The increasing rate of heat sealing strength on $\mathrm{C} / \mathrm{C}$ interface is obviously weakened below $105^{\circ} \mathrm{C}$. As the temperature increases, the heat sealing strength increases continuously and slowly. At the same heat sealing temperature, the heat sealing strength of BOPP also increases with the increasing coating thickness.
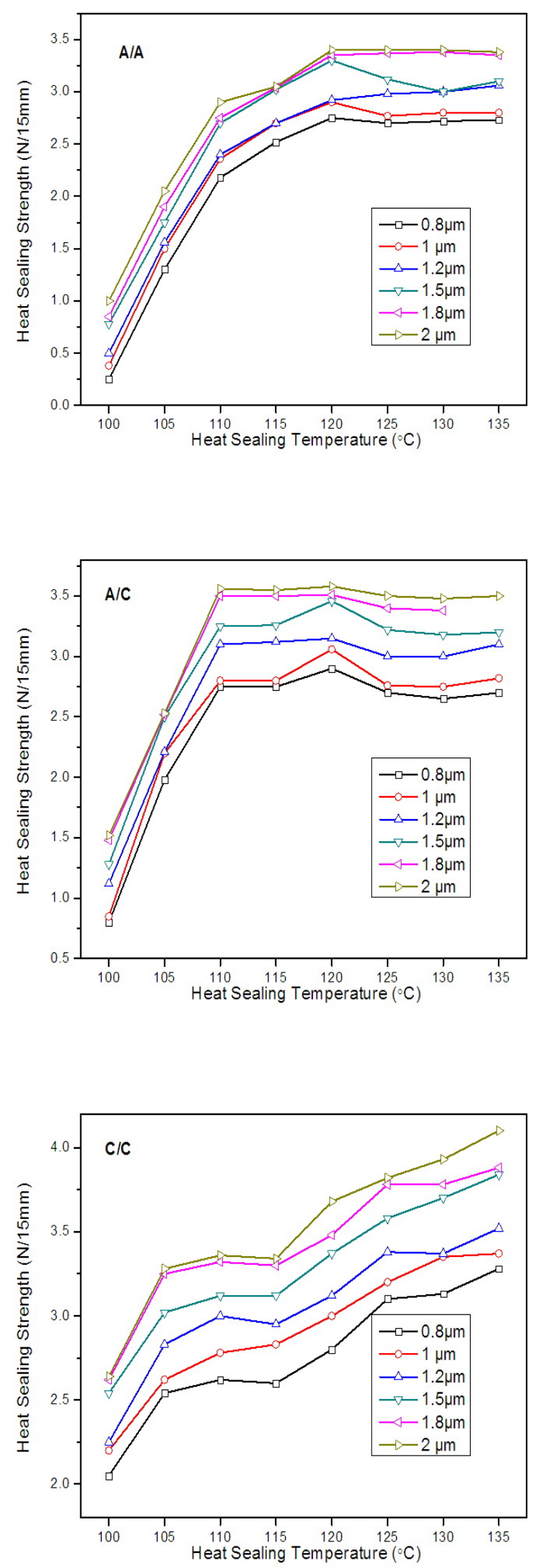

Figure 2. Heat sealing strength of BOPP with different thickness. 


\section{Relationship between Haze and coating thickness}

As mentioned above, increasing the coating thickness suitably could enhance the heat sealing strength of BOPP films. Will changed coating thickness affect other performances of BOPP films? To make clear this question, we detect the haze of film samples with different coating thickness. The relationship of haze and coating thickness is shown in Fig. 4. The haze of BOPP films increases remarkably with increasing coating thickness. That means that the increasing coating thickness enhances the heat sealing strength, while decrease the transparency of BOPP films.

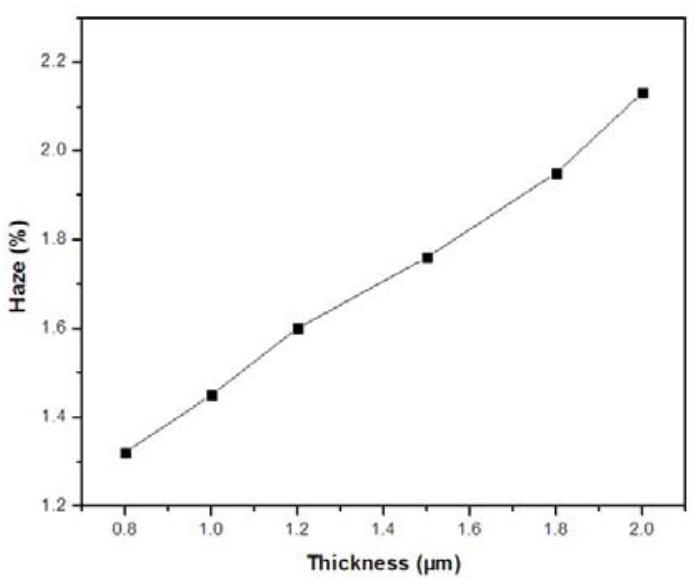

Figure 3. Weight loss of the copolymer films against degradation time.

\section{The thickness and friction coefficient}

To investigate the relation of thickness and friction coefficient, we measured the dynamic/static friction coefficient of the interfaces with different coating thickness (Fig. 4). We used I/O/M to represent different coated interfaces (polyvinyl alcohol surface, acrylic surface and metallic surface, respectively). From the curve trend of friction coefficient with the increasing thickness, we can see that the thickness does not affect the coefficient of static friction. The changes of coefficient of static friction and coefficient of dynamic friction with coating thickness have the similar trends.

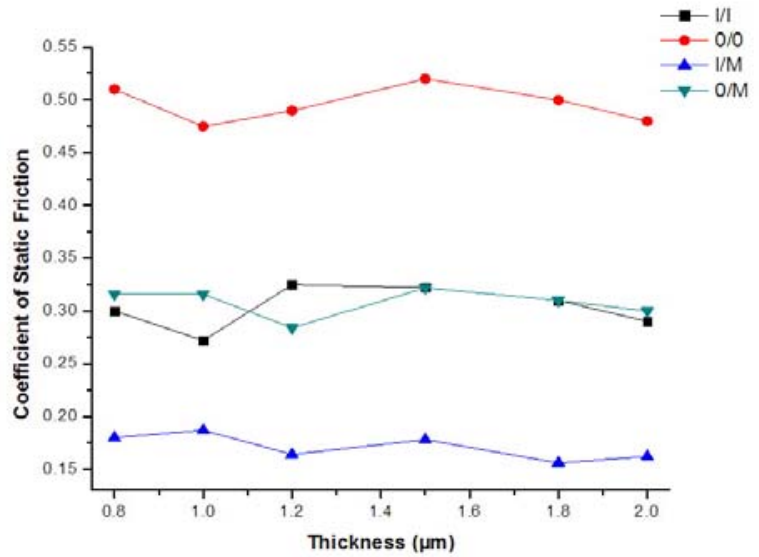

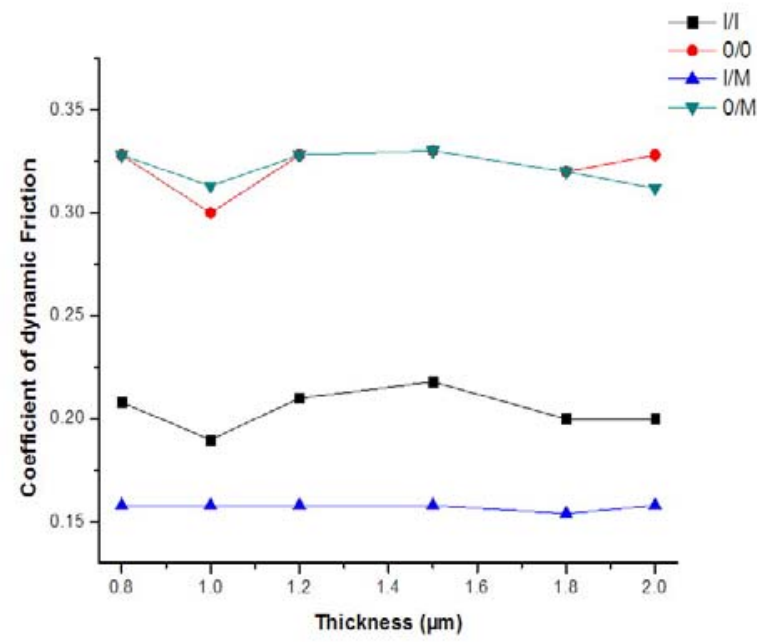

Figure 4. Coefficient friction of dynamic /static of the two curves with thickness curves.

\section{CONCLUSIONS}

We tested various performance indicators of heatsealing BOPP films with different surface coating thickness in this paper. The results show that with the same coating thickness of BOPP films, the heat-sealing strengths of $\mathrm{A} / \mathrm{A}$ and $\mathrm{C} / \mathrm{C}$ interfaces increase with increasing temperature. At the same temperature, the heat sealing strength also increases with increasing coating thickness. As the film coating thickness increases from different heat sealing interfaces, it exposures a little impact on the friction coefficient, and the changes of static and dynamic coefficient friction display the similar trends. The fluctuation in the curves may be caused by a variety roughness of film surface. The haze of BOPP films increase remarkably with increasing coating thickness, which means the coating thickness has a greater impact on haze.

\section{ACKNOWLEDGMENT}

This work was financially supported by Natural Science Foundation of Hainan Province of China (512111).

\section{REFERENCES}

[1] Keunsuk P. Chang, E. Ballico, and C. Dicostanzo, United States Patent Application: 20060177650, "Sealable Biaxially Oriented Polypropylene Film for Packaging,” 2006

[2] M. B. Elias, R. Machado and S. V. Canevarolo, "Thermal and Dynamic-Mechanical Characterization of Uni-and Biaxially Oriented Polypropylene Films,” J. Therm. Anal. Cal., vol. 59, Jan. 2000, pp. 143-155, doi:10.1023/A:1010187913049.

[3] S. Kim, and M. R. Stephans, United States Patent: 6733898, "Resin Compositions for Producing Biaxially Oriented Polypropylene Films,” 2004

[4] H.-Y. Nie, M. J. Walzak and N. S. McIntyre, "Draw-RatioDependent Morphology of Biaxially Oriented Polypropylene Films as Determined by Atomic Force Microscopy,” Polymer, vol. 41, Mar. 2000, pp. 2213-2218, doi:10.1016/S0032-3861(99)00397-3. 
[5] F. Sadeghi and P. J. Carreau, "Properties of Uniaxially Stretched Polypropylene Films,” Can. J. Chem. Eng., vol. 86, Dec. 2008, pp.1103-1110, doi: 10.1002/cjce.20109.

[6] S. H. Tabatabaei, P. J. Carreau and A. Ajji, "Rheological and Thermal Properties of Blends of a Long-Chain Branched Polypropylene and Different Linear Polypropylenes,” Chem. Eng. Sci., vol. 64, Nov. 2009, pp. 4719-4731, doi:10.1016/j.ces.2009.04.009.

[7] S. H. Tabatabaei, P. J. Carreau and A. Ajji, "Structure and Properties of MDO Stretched Polypropylene,” Polymer, vol. 50, Jul. 2009, pp. 3981-3989, doi:10.1016/j.polymer.2009.06.059.

[8] Y. Koike and M. Cakmak, “Atomic Force Microscopy Observations on the Structure Development During Uniaxial
Stretching of PP From Partially Molten State: Effect of Isotacticity,” Macromolecules, vol. 37, Feb. 2004, pp. 2171-2181, doi: 10.1021/ma030250a.

[9] F. Sadeghi, S. H. Tabatabaei, A. Ajji*and P. J. Carreau, "Poperties of Uniaxially Stretched Polypropylene Films: Effect of Drawing Temperature and Random Copolymer Content,” Can. J. Chem. Eng., vol. 88, Dec. 2010, pp. 1090-1098, doi:10.1002/cjce.20372.

[10] S. Rettenberger, L. Capt, H. Munstedt, K. Stopperka and J. Sanze, "Uniaxial Deformation Behavior of Different Polypropylene Cast Films at Temperatures Near the Melting Point,” Rheol. Acta, vol. 41, Jan. 2002, pp. 332-336, doi:10.1007/s00397-002-0239-x. 